\title{
Uso de cactáceas na alimentação animal e seu armazenamento após colheita
}

\author{
Carvalho, C.B.M. ${ }^{1}$; Edvan, R.L. ${ }^{\text {; }}$ Carvalho, M.L.A.M. ${ }^{1}$; Reis, A.L.A. ${ }^{1}$ e Nascimento, R.R. ${ }^{2}$
}

'Universidade Federal do Piaú (UFPI). Bom Jesus-PI, Brasil.

¿Universidade Federal de Campina Grande (UFCG). Patos-PB, Brasil.

\section{PalaVRas chaVe ADICIONAIS}

Cactos.

Forragem.

Ruminantes.
Alimentos alternativos.

\section{RESUMO}

Devido às suas características fisiológicas de economia e uso da água, as cactáceas permanecem suculentas durante períodos de seca, constituindo uma fonte alimentar alternativa principalmente durante a escassez de forragem e como fonte de água para os animais. Dentre as cactáceas mais usadas como forrageiras no Brasil tem o mandacaru, xiquexique, facheiro, coroa-de-frade e palma forrageira. O método mais usual da colheita das cactáceas é manual, com fornecimento direto no cocho para os animais, no entanto esta atividade diária aumenta a mão de obra e onera os custos de produção. $O$ armazenamento desse material após a colheita por longos dias, surge como uma alternativa para minimizar os custos, e até mesmo transportar para longas distâncias, aumentando assim a segurança alimentar dos rebanhos, principalmente nas épocas secas. No entanto pouco são os trabalhos quanto ao efeito do período de armazenamento na composição e qualidade nutricional dessas plantas na alimentação animal. Dessa forma, essa revisão foi desenvolvida com o objetivo de abordar o uso das cactáceas na alimentação animal e o seu armazenamento após a colheita.

\section{Use of cacti in animal feed and post-harvest storage}

\section{SUMMARY}

Due to their physiological characteristics of water use and economy, cacti remain succulent during periods of drought, constituting an alternative feed source, mainly during forage scarcity and as a source of water for animals. Among the most used cactaceae as forages in Brazil has mandacaru, xiquexique, facheiro, coroa-de-frade and forage palm. The most common method of harvesting cacti is manual, with direct feed into the trough for animals, however this daily activity increases manpower and costs production costs. The storage of this material after harvesting for long days appears as an alternative to minimize costs, and even transport for long distances, thus increasing the food security of the herds, especially in the dry seasons. However, there is little work on the effect of the storage period on the composition and nutritional quality of these plants in animal feed. Thus, this review was developed with the objective of approaching the use of cactaceae in animal feed and their storage after harvest.

\section{INTRODUÇÃO}

Um dos principais entraves da região Tropical, é a estacionalidade da produção de forragem ocasionada pela distribuição irregular das chuvas. No entanto as cactáceas tem sido frequentemente utilizadas como um fonte alimentar alternativa, e são vários os estudos que demonstram a eficiência destas na alimentação para ruminantes (Santana Neto et al. 2015; Peixoto et al. 2018; Bravo et al. 2018).

Essas espécies além de suprir parte da demanda nutricional dos animais, também influenciam a ingestão de água, reduzindo a necessidade de fornecimento de água para os animais, o que deve ser considerado como uma excelente estratégia alimentar onde esse nutriente torna-se limitado (Neto et al. 2016, p. 328). Devido às suas características fisiológicas de economia e uso da água (Macedo et al. 2017, p. 4), permanecem suculentas durante períodos de seca. Por outro lado, essas cactáceas apresentam alto custo de mão de obra no manuseio e preparo da forragem, requerendo que técnicas de manejo sejam conduzidas com sustentabilidade das espécies e baixo custo de produção (Silva et al. 2010b, p. 124).

Com intuito de diminuir as influências climáticas nos sistemas de produção produzidos em regiões se- 
miáridas, os métodos de conservação de forragem são indicados como o principal recurso na tomada de decisão para contribuição nutricional do rebanho (Lima Júnior et al. 2013, p. 34). Como opção pode-se utilizar técnicas de conservação como a ensilagem e fenação, quem promovem a preservação dos nutrientes presentes nas forragens fresca, resultando no armazenamento, com perdas nutricionais mínimas, por longos períodos.

Com relação à conservação de forragem das plantas das regiões Tropicais do Brasil, o processo de fenação tem permitido o melhor aproveitamento de espécies forrageiras com técnicas e manejos sustentáveis (Silva et al. 2010b, p. 124). Porém fazer feno de cactáceas não seria nutricionalmente viável, porque poderia ocorrer perdas de nutrientes, já que de modo geral as cactáceas apresentam alto teor de umidade, e para tal sucesso da prática, a rápida desidratação não ocorreria, devido a sua fisiologia que impediria a perda de água. Apesar da fenação apresentar facilidades durante suas operações, a ensilagem é a técnica de conservação mais indicado para as regiões secas, visto que a água é conservada na forragem e contribui para dessedentação dos animais. No entanto, a ensilagem é um processo complexo e susceptível a vários fatores, principalmente a espécie forrageira (Lima Júnior et al. 2013, p. 34). Em geral, os teores de matéria seca das cactáceas são baixos (Goes Neto 2014, p. 32), o que também não seria adequado para ensilar, já que valores inferiores a 30\% de matéria seca, estão relacionados às possíveis limitações na ação de clostrídios.

O método usual de colheita destas cactáceas forrageiras é manual, com colheita diária, e fornecidas aos animais direto no cocho. Apesar da colheita manual ser o método de melhor aproveitamento, essa prática aumenta a mão de obra e consequentemente onera os custos de produção (Silva et al. 2017, p. 762). O pastejo direto poderia ser uma alternativa para diminuir os custos no fornecimento dos animais, no entanto, pode comprometer o cultivo de algumas espécies de cactáceas, como a palma forrageira, devido a danos oriundos pelos animais a planta.

Neste contexto, para minimizar os custos relacionados ao corte, pode-se fazer o armazenamento do material colhido, bem como o transporte para localidades distantes. Todavia a duração do tempo de armazenamento do material pode promover perdas significativas dos nutrientes e/ou promover produção de outros constituintes que podem prejudicar o consumo e sanidade do animal. Por outro lado, poucas são as informações quanto ao armazenamento de cactáceas após colheita e o efeito deste material armazenado sobre a alimentação dos animais. Dessa forma essa revisão foi confeccionada com objetivo de discutir o uso das cactáceas na alimentação animal e a viabilidade do seu armazenamento após a colheita.

\section{CACTÁCEAS}

A Família Cactaceae faz parte das Angiospermas e representa o segundo grupo mais numeroso da região neotropical (Bravo Filho et al. 2018, p. 42), formada por quase aproximadamente 1500 espécies. O Brasil é considerado o terceiro maior centro de diversidade dessa família, com 260 espécies, dentre as quais 187, ou seja, 72\% são endêmicas (Zappi et al. 2015).

As cactáceas, em geral, são caracterizadas pela alta eficiência de uso da água, e segundo Silva et al. (2012, p. 41), habitam em condições edafoclimáticas caracterizadas por elevadas temperaturas, precipitações pluviométricas irregulares e baixa fertilidade natural do solo.

É um grupo de importância econômica com diversas utilidades, sendo relacionadas a várias práticas, como ornamentação, medicina tradicional, usos místico-culturais, culinária, produção de forragem, como bioindicador da chuva, construção de cercas vivas e produtos diversos. (Bravo Filho et al. 2018, p. 50). No nordeste brasileiro as espécies da família das cactáceas são muito utilizadas como recurso forrageiro para os rebanhos, principalmente, na época seca do ano.

\section{Metabolismo das cactáceas}

Fisiologicamente, as cactáceas caracterizam-se por apresentarem um tipo específico de metabolismo, denominado metabolismo ácido das crassuláceas, ou simplesmente MAC (Taiz \& Zeiger 2013, p. 221).

O MAC é uma adaptação fotossintética que surgiu, independentemente, várias vezes na evolução das plantas vasculares, possivelmente por meio da reorganização de vias metabólicas já existentes em plantas com metabolismo C3 (West-Eberhard et al. 2011, p. 311). Esse sistema altamente eficiente das plantas com fisiologia MAC é decorrente, principalmente, de seu comportamento estomático, os quais se abrem durante a noite e fecham-se durante o período quente e seco do dia (Taiz \& Zeiger 2013, p. 223). O efeito osmótico das acumulações noturnas de ácidos orgânicos vacuolares permite a aquisição noturna de água do fluxo de transpiração e também do orvalho, e o armazenamento temporário de água nos vacúolos (Lüttge 2011, p. 2). Desta forma, o dióxido de carbono absorvido à noite, é fixado na forma de ácido málico. Como durante o dia os estômatos estão fechados, as plantas com fisiologia MAC não perdem água, o ácido málico fixado é então descarboxilado, liberando $\mathrm{CO}_{2}$, que posteriormente será fixado em carboidrato pelo ciclo de Calvin-Benson (Taiz \& Zeiger 2013, p. 223).

Devido a este traço fisiológico das plantas MAC, confere a capacidade de lidar com o estresse do suprimento limitado de água (Lüttge 2011, p. 2), permitindo uma melhor eficiencia no uso da mesma em comparação com as plantas de fotossintese C3 e C4.

\section{CACTÁCEAS UtILIZADAS NA ALIMENTAC̄̃̃ ANIMAL}

Entre as cactáceas utilizadas na alimentação animal no Brasil, a palma forrageira é a mais difundida e cultivada entre os produtores rurais do país. A palma é uma forrageira de alta produtividade, consumida por várias espécies animais e também pelo homem, sua utilização são inúmeras e variam desde o consumo in natura, até a produção de farelos ou como emoliente adicionada a restos culturais, palhadas e subprodutos industriais, compondo até $80 \%$ da dieta dos animais, sobretudo no período de estiagem (Soares II \& Silva Júnior 2012, p. 4). Também já vem sendo utilizada para produção de silagem apresentando uma silagem de boa qualidade 
(Nogueira et al. 2016, p. 250). Carvalho (2017, p.78) estudando variedades de palma forrageira Doce Miúda e Orelha de Elefante Mexicana na forma de silagem, encontrou resultados satisfatórios para composição química, apresentando perdas fermentativas mínimas e com alto índice de recuperação de matéria seca. Além disso, as silagens apresentaram resultados adequados para os teores de $\mathrm{pH}, \mathrm{N}-\mathrm{NH}_{3}$ e capacidade tampão, indicando adequada fermentação.

Em determinadas áreas do semiárido nordestino do Brasil onde as palmas forrageiras (Opuntia ficus indica Mill, e Nopalea cochenillifera Salm-Dyck) não se adaptam ou apresentam baixos rendimentos, as cactáceas nativas xiquexique [Pilosocereus gounellei (A. Weber ex K. Schum.) Byl ex Rowl.] e mandacaru (Cereus jamacaru DC.) se sobressaem em relação a essas espécies introduzidas, e são utilizadas durante períodos de seca prolongados como volumosos estratégicos na alimentação dos ruminantes (Silva et al. 2012, p. 34).

Fazendo conhecimento local sobre cactáceas em comunidades rurais na mesorregião do sertão da Paraíba, Brasil, Lucena et al. (2012, p. 286) registraram o uso de cinco espécies, sendo elas Cereus jamacaru DC. (mandacaru), Melocactus sp. (coroa-de-frade), Pilosocereus chrysostele (Vaupel) Byles \& G. D. Rowley (facheiro), Nopalea cochenillifera (L.) Salm-Dyck (palma doce) e Pilosocereus gounellei (F.A.C. Weber) Byles \& G. D. Rowley (xiquexique), todas utilizadas como forrageiras. Já Bravo Filho et al. (2018, p. 48), ao realizar um levantamento etnobotânico da família Cactaceae no estado de Sergipe, Brasil, mencionaram seis espécies de cactos utilizadas na alimentação dos animais, tratando-se de palma forrageira (Nopalea cochenillifera), mandacaru (Cereus jamacaru), facheiro (Pilosocereus catingicola), xique-xique (Pilosocereus gounellei), quipá (Tacinga inamoena) e coroa-de-frade (Melocactus zehntneri), sendo a palma forrageira a mais utilizada inclusive com produção comercial, seguida do mandacaru, principalmente no período de estiagem. A categoria forragem, se mostrou importante em outras localidades de diferentes regiões do Brasil (Lucena et al. 2012, p. 287).

\section{PALMA FORRAGEIRA}

A palma forrageira é um importante recurso forrageiro para as regiões semiáridas do Brasil, devido ao seu potencial de produção de biomassa em condições de baixa pluviosidade com elevada capacidade de produção de biomassa se comparada à vegetação nativa do bioma Caatinga (Neto et al. 2016, p. 323), região essa que possui em algumas localidades solos rasos, pedregosos ou arenosos, com pouca matéria orgânica, porém ricos em minerais solúveis e $\mathrm{pH}$ próximo de sete (Oliveira 2011, p. 49), não sendo essas características de solo encontrada em todo semiárido, existem localidades que apresentam solos profundos e com elevados níveis de fertilidades. A palma era cultivada geralmente nos piores solos da propriedade, hoje essa espécie é plantada nos melhores solos, sendo considerado por muitos produtores como uma cultura nobre, pois apresenta em termos de produtividade elevada resposta aos níveis de fertilidade do solo.

Os gêneros Opuntia e Nopalea estão presentes às espécies de palma mais utilizadas como forrageiras
(Macêdo et al. 2017, p. 4). Entre as espécies mais difundidos no Nordeste brasileiro, citam-se a Opuntia ficus-indica Mill, com as cultivares Gigante e Redonda, e a Nopalea cochenillifera Salm Dyck, cuja cultivar é a palma Miúda (Silva et al. 2015, p. 11). Entre os motivos que levaram essas espécies a serem as mais cultivadas está a adaptação a regiões de clima Tropical do Brasil e ao fácil manuseio dessa espécie no momento do plantio e colheita dos cladódios. Além disso, a produção precoce de palma, quando irrigada, é importante para proporcionar alimentos aos rebanhos já no primeiro período seco após a implantação da cultura (Rocha et al. 2017, p. 366).

Apesar de não nativas do semiárido brasileiro, essas planta se adaptaram às condiçõos da região e apresentam altas produções de matéria seca por unidades de área (Silva \& Santos 2006, p. 2). Pesquisa realizada por Cavalcante et al. (2014, p. 429) obtiveram produtividades médias de 379,83, 392,83 e 480,17 t MV / ha a cada 02 anos para as cultivares Gigante, Redonda e Miúda respectivamente, a diferentes densidades de cultivo, e produtividade de matéria seca média de 24,07, 23,32 e 37,52 t MS/ha a cada 02 anos. Em contra partida, Peixoto et al. $(2018$, p. 37) encontraram uma produtividade média de 41,16 t MV ha-1 para variedade Gigante exposto ao sol e com adubação orgânica, e de 9,0 t MS e $8,96 \mathrm{t} \mathrm{MS} / \mathrm{ha}^{-1}$ para o plantio exposto ao sol e adubado, respectivamente. Por outro lado, Rocha et al. (2017, p. 367) estudando as características produtivas de genótipos de palma forrageira irrigada em intervalos de corte, obtiveram maior massa de forragem aos 16 meses após o plantio para Orelha de Elefante Mexicana (763,50 t de MV/ha), em relação a Miúda (388,75 t de $\mathrm{MV} / \mathrm{ha}$ ) e ao IPA 20 (426,75 t de MV/ha).

Dentre os genótipos mais utilizados na alimentação dos ruminantes, destacam-se Gigante (Opuntia ficus-indica L. Mill), Redonda (Opuntia sp.) e Miúda (Nopalea cochenillifera Salm-Dyck), sendo a Miúda a que apresenta melhor valor nutritivo em relação as demais. Porém, no ponto de vista agronômico a palma Orelha de Elefante Mexicana (Opuntia stricta) tem-se mostrado menos exigente em nutrientes, mais tolerante às condições de estresse hídrico e também tem apresentado maior produção de matéria seca por unidade de área do que os demais genótipos (Silva et al. 2017, p. 762). Todavia, Silva et al. (2015, p. 11) enfatizam que os clones IPA Sertânia (Nopalea cochenillifera Salm Dyck), Miúda (N. cochenillifera Salm Dyck) e Orelha de Elefante Mexicana [Opuntia stricta (Haw.) Haw.] são resistentes à praga cochonilha-do-carmim (Dactylopius sp.), e suas áreas de cultivo estão em expansão no Nordeste brasileiro.

Testando o potencial das cactáceas como alternativa alimentar para ruminantes no semiárido, Santana Neto et al. (2015, p. 4429) relata que, das várias espécies de palma introduzidas, apenas três apresentaram ótima adaptação: a palma Graúda ou Gigante (Opuntia fícus-indica Mill), a palma Miúda (Nopalea cochenillifera, Salm-Dyck) e a palma Redonda (Opuntia sp.), o que justifica grande quantidade de trabalhos com essas variedades (Tabela I).

As principais características bromatológicas da palma forrageira são alto conteúdo de água, minerais, 
ácidos orgânicos e de carboidratos, e baixo teor de proteína (Neto et al. 2016, p. 323). Sua composição química é variável em relação função de características intrínsecas e extrínsecas, como ecotipo utilizado, solo, clima, adubação, período de corte e tratos culturais (Rodrigues et al. 2016, p. 43). E independentemente do gênero, a palma apresenta ainda baixos teores de matéria seca, fibra em detergente neutro e fibra em detergente ácido (Tabela I). Sendo os aspectos limitantes no fornecimento de palma para alimentação de ruminantes o seu baixo teor de fibra associado com baixo teor de proteína bruta.

De acordo a Tabela I a palma Gigante é a que apresenta menor valor nutricional, corroborando com Silva e Santos (2006, p. 3), onde também atribuem a palma Gigante menor valor nutritivo e consequentemente menor aceitabilidade pelo animal, diferente da palma Miúda que é mais aceita. Isso deve a maior quantidade de MS presente nessa cactácea, também evidenciada no referido estudo. Entretanto o gênero Opuntia apresentam maior teor de PB. Em geral, os baixos níveis de proteína presentes na palma, bem como a matéria seca e fibra reduzidas, comumente, podem levar os animais a desenvolverem distúrbios digestivos como diarreia, caso consumida exclusivamente. Por esse motivo, deve-se associar a palma com uma fonte de alimento que apresente uma certa quantidade de fibra fisicamente efetiva que desempenhe um adequado funcionamento do rúmen do animal como também deve ser enriquecida com uma fonte de proteína (Rodrigues et al. 2016, p. $44)$, pois estas estão no limite inferior às necessidades dos microrganismos do rúmen. Ferreira et al. (2009, p. 325) enfatizam vários estudos onde a palma forrageira foi associada com diferentes volumosos, não sendo observados diarreia, perda de peso, alterações no consumo de matéria seca ou queda no teor de gordura no leite em dietas para bovinos leiteiros.

A palma forrageira é rica em carboidratos, principalmente não fibrosos (Wanderley et al. 2002, p. 276), considerada uma fonte energética de grande potencial para alimentação de ruminantes (Peixoto et al. 2018, p. 36), o que tem despertado o interesse para sua utilização em substituição a concentrados energéticos, além de baixa porcentagem de constituintes da parede celular e alto coeficiente de digestibilidade de matéria seca (Oliveira et al. 2011, p. 53). Ainda é rica em vitaminas A, complexo B e C, e minerais como Cálcio, Magnésio, Sódio, Potássio, e 17 tipos de aminoácidos (Nunes 2011, p. 59).

\section{XIQUeXIQUe, MANDACARU, COROA-DE-FrAdE E FACHEIRO}

$\mathrm{O}$ xiquexique é uma planta muito importante na cadeia alimentar do bioma caatinga brasileiro, por fornecer frutos, néctar e hastes que são bastante utilizadas na alimentação dos ruminantes, principalmente ovinos e caprinos (Magalhães 2014, p. 23). Geralmente é utilizado como a última alternativa dos agropecuaristas para salvar seus animais, devido à dificuldade de sua utilização em função da grande quantidade de espinhos, quando os agropecuaristas não encontram mais mandacaru, macambira e coroa-de-frade, eles recorrem ao xiquexique para alimentar os animais (Cavalcanti \& Resende 2007, p. 22).
O mandacaru é uma cactácea que ocorre nas caatingas nordestinas do Brasil de grande importância para a sustentabilidade e conservação da biodiversidade desse bioma. Seus frutos são alimentos para pássaros e animais silvestres dessa região, e na seca os agricultores cortam o mandacaru e queimam seus espinhos para alimentar seus rebanhos de caprinos, ovinos e bovinos (Cavalcanti \& Resende 2006a, p. 255). Contudo, de acordo com Silva et al. (2010b, p. 124), essa forrageira apresenta como limitações o lento crescimento e o alto custo da mão de obra no processamento com o corte da planta, a queima ou retirada dos espinhos e a trituração do material forrageiro. Apresenta ainda baixa capacidade de produzir fitomassa. De acordo com Cavalcanti e Resende (2006a, p. 258), o mandacaru sem espinhos (Cereus hildemannianus K. Schum.), aos 360 dias após o plantio, apresenta variações de 132,3 a 151,1g planta $^{-1}$ de matéria seca. Já Silva et al. (2012, p. 41) encontraram produção de $1.304,1 \mathrm{~kg}$ de MS/ano, no tratamento com maior densidade populacional.

No Brasil e em alguns países da América Latina, vêm-se utilizando como alternativa alimentar cactáceas do gênero Melocactus (coroa-de-frade) e Pilosocereus (facheiro). Bem como o facheiro (Cereus squamosus), que assim como o mandacaru, também é fonte de caibros e ripas utilizados na construção rural, e como as demais cactáceas é utilizado na alimentação animal e é rico em água.

A qualidade como alimento das cactáceas para os animais estão na alta aceitabilidade e digestibilidade, no alto teor de carboidratos solúveis, e no baixo teor de fibra. Segundo Silva et al. (2010a, p. 5), as oscilações das porcentagens de MS das cactáceas estão relacionada aos fatores climáticos, idade da planta, época do ano, e manuseio no preparo da amostra (retirada dos espinhos). Entretanto, a Tabela II demonstra que a variação na composição química das cactáceas nativas do Brasil está relacionada também as espécies.

De acordo a Tabela II as médias de MS, MO, PB, FDN, FDA e EE são, respectivamente, de 166,0, $841,8,63,8,445,5,287,9$ e $33,4 \mathrm{~g} \mathrm{~kg}^{-1}$ para xiquexique, e $218,0,868,0,88,2,456,7,345,3$ e $15,9 \mathrm{~g} \mathrm{~kg}^{-1}$ para o mandacaru. Evidenciando que o mandacaru apresenta médias superiores na sua composição química em relação às demais cactáceas. Todavia, há necessidade de mais estudos em relação às espécies facheiro e coroade-frade para realizar uma melhor comparação entre as espécies de cactáceas nativas do Brasil.

\section{MANEJO dE COLHEITA}

A palma, de maneira geral, é colhida em intervalos de dois anos em condições de sequeiro, ou de acordo com o desenvolvimento da cultura, segundo as condições do solo e clima, posteriormente poderá ser feito o corte anualmente. Devido a estrutura da cultura, a palma é colhida manualmente e transportada por tração animal até o seu local de uso. Em geral, essa operação é realizada diariamente, aumentando os custos de produção (Silva et al. 2017, p. 762), e embora onere os custos, é a maneira mais racional de utilização da palma. Silva e Santos (2006, p. 6) relatam que a palma também pode ser oferecida por pastejo, porém promovem muitas perdas por causa dos danos ocasionados às 
Tabela I. Composição química de diferentes variedades de palma forrageira (Chemical composition of different varieties of forage palm).

\begin{tabular}{|c|c|c|c|c|c|c|c|c|}
\hline \multirow{3}{*}{$\begin{array}{l}\text { Variedade } \\
\text { (Espécie) }\end{array}$} & MS & $\mathrm{MO}$ & PB & FDN & FDA & MM & EE & \multirow{2}{*}{ Autor/Ano } \\
\hline & $\mathrm{g} \mathrm{kg}^{-1}$ & \multicolumn{6}{|c|}{$\mathrm{g} \mathrm{kg}^{-1} \mathrm{MS}$} & \\
\hline & 110,0 & - & 50,0 & 281,0 & 222,0 & - & - & Santos et al. (2006, p. 23) \\
\hline \multirow[t]{2}{*}{$\begin{array}{l}\text { Redonda } \\
\text { (Opuntia sp.) }\end{array}$} & 109,3 & 887,1 & 51,4 & - & - & 112,9 & 17,8 & $\begin{array}{l}\text { Valadares Filho et al. } \\
\qquad(2006, \text { p. 13) }\end{array}$ \\
\hline & 60,7 & 822,5 & 52,1 & 270,5 & 193,2 & 177,5 & 32,0 & Cavalcante et al. (2014, p. 429) \\
\hline \multirow[t]{3}{*}{ Média } & 93,33 & 854,8 & 51,2 & 275,8 & 207,6 & 145,2 & 24,9 & \\
\hline & 126,3 & 934,1 & 44,5 & 261,7 & 200,5 & 65,9 & 8,4 & Wanderley et al. (2002, p. 276) \\
\hline & 102,0 & - & 53,0 & 269,0 & 224,0 & - & - & Santos et al. (2006, p. 23) \\
\hline \multirow{3}{*}{$\begin{array}{l}\text { Gigante } \\
\text { (Opuntia fícus-indica } \\
\text { Mill) }\end{array}$} & 88,2 & 897,9 & 50,2 & 276,9 & 179,3 & 102,1 & 19,8 & $\begin{array}{l}\text { Valadares Filho et al. } \\
(2006, \text { p. 13) }\end{array}$ \\
\hline & 63,7 & 840,7 & 54,2 & 283,0 & 209,3 & 159,4 & 29,8 & Cavalcante et al. (2014, p. 429) \\
\hline & - & 781,8 & 47,3 & - & 187,1 & 134,0 & 12,6 & Peixoto et al. (2018, p. 39)* \\
\hline \multirow[t]{2}{*}{ Média } & 95,05 & 863,6 & 49,8 & 272,7 & 200,0 & 115,4 & 17,7 & \\
\hline & 103,4 & 797,1 & 49,9 & 394,2 & 121,8 & 202,9 & 20,0 & Goes Neto $(2014$, p. 32$)$ \\
\hline \multirow{2}{*}{$\begin{array}{l}\text { OEM } \\
\text { (Opuntia stricta) }\end{array}$} & 127,3 & 914,7 & 33,2 & - & 172,9 & 85,3 & 12,2 & Silva et al. (2017, p. 763$)$ \\
\hline & 110,5 & 854,8 & 54,2 & 263,3 & 218,0 & 145,2 & 13,6 & Carvalho $(2017, \text { p. } 43)^{*}$ \\
\hline \multirow[t]{2}{*}{ Média } & 113,7 & 855,5 & 45,8 & 328,8 & 170,9 & 144,5 & 15,3 & \\
\hline & 130,6 & 930,0 & 33,4 & 166,0 & 136,6 & 70,0 & 17,1 & Valadares Filho et al. (2006, p. 13) \\
\hline \multirow{4}{*}{$\begin{array}{l}\text { Doce miúda } \\
\text { (Nopalea cochenillife- } \\
\text { ra Salm Dyck) }\end{array}$} & 77,6 & 824,8 & 43,1 & 328,1 & 199,7 & 175,3 & 30,9 & $\begin{array}{l}\text { Cavalcante et al. } \\
(2014, \text { p. } 429)\end{array}$ \\
\hline & 128,3 & 829,2 & 79,2 & 350,1 & 148,6 & 170,8 & 18,4 & Goes Neto $(2014$, p. 32$)$ \\
\hline & 140,2 & 913,2 & 32,5 & - & 200,1 & 86,8 & 11,3 & Silva et al (2017, p. 763) \\
\hline & 122,5 & 848,7 & 33,8 & 250,2 & 203,4 & 151,3 & 14,1 & Carvalho $(2017, \text { p. } 43)^{*}$ \\
\hline Média & 119,8 & 869,2 & 44,4 & 273,6 & 177,7 & 130,8 & 18,4 & \\
\hline
\end{tabular}

*Média dos tratamentos; OEM: Orelha de Elefante Mexicana; MS: matéria seca; MO: matéria orgânica; PB: proteína bruta; FDN: fibra em detergente neutro; FDA: fibra em detergente ácido; MM: matéria mineral; EE: extrato etéreo.

*Average treatment; OEM: Orelha de Elefante Mexicana; MS: dry matter; MO: organic matter; PB: crude protein; FDN: neutral detergent fiber; FDA: acid detergent fiber; MM: mineral matter; EE: ethereal extract.

plantas pelo pastejo e pisoteio dos animais. A colheita do xiquexique e do mandacaru também é feita manualmente pela retirada das brotações laterais utilizando-se ferramenta adequada. Posteriormente, o material colhido é transportado até o local de fornecimento aos animais, onde os espinhos são retirados normalmente por meio de queima (Silva et al. 2013, p. 56).

Assim como na cana de açúcar, a colheita feita de uma única vez permite uma melhor logística dentro da propriedade, pois os gastos concentram-se em apenas um único período, principalmente em lugares ou épocas em que o produtor não pode contar com a mão de obra diariamente para essa atividade, além de colheita em épocas que as cactáceas apresentem melhor valor nutritivo. Para realizar a colheita de áreas grandes seria necessário fazer o armazenamento do material in natura ou fazer silagem. O armazenamento in natura de cactáceas pode comprometer a qualidade química do material com o passar do tempo, e fazer silagem com essas espécies ainda é uma opção pouco difundida, que precisa de mais estudos.

\section{ARMAZENAMENTO PÓS-COLHEITA}

A possibilidade de armazenar as cactáceas após a colheita para fornecimento aos animais sem perdas ele- vadas do valor nutricional é uma opção válida, já que a maioria dos criadores colhe, processa e fornece diariamente, onerando os custos na produção. No caso de um palmal, além de uma despadronização do plantio, dificulta tarefas como a adubação, além de dificultar a atividade. $\mathrm{O}$ armazenamento pós-colheita pode ser uma alternativa para diminuir os custos com a colheita e transporte do material, contudo o armazenamento deve ocorrer em local com sombra ou coberto, contanto que seja ventilado. Além disso, os ramos das cactáceas devem ser amontoados inteiros, realizando o fracionamento do material no momento do uso. Estudando o manejo e composição química de Pilosocereus gounellei, em caatinga no sertão cearense, Magalhães (2014, p. 68) não encontrou diferença para os teores de matéria mineral, proteína bruta, extrato etéreo, fibra em detergente neutro e ácido, carboidratos totais, matéria seca total, carboidratos não-fibrosos e matéria orgânica em relação ao local de armazenamento (árvore ou galpão).

Com relação ao período de armazenamento, Magalhães (2014, p. 94) retrata que o xiquexique seja armazenado de forma in natura e a retirada dos acúleos seja feita somente na hora do fornecimento aos animais, pois dessa forma não acarreta nenhuma perda nos teores nutricionais da planta, e podem ser armazena- 


\begin{tabular}{lccccccl}
\hline \multicolumn{6}{l}{ Tabela II. Composição química de diferentes cactáceas (Chemical composition of different cacti). } \\
\cline { 2 - 6 } Espécies & MS & MO & PB & FDN & FDA & EE & Autor (Ano) \\
\cline { 2 - 6 } & $\mathrm{g} \mathrm{Kg}^{-1}$ & & & $\mathrm{~g} \mathrm{Kg}^{-1} \mathrm{MS}$ & & & \\
\hline \multirow{3}{*}{ Xiquexique } & 109,7 & - & 58,9 & 503,4 & - & - & Cavalcanti e Resende (2007, p. 24) \\
& 207,2 & 857,4 & 73,8 & 383,2 & 269,7 & 12,4 & Silva et al. (2010b, p. 125) \\
& 227,1 & 835,1 & 63,2 & 413,3 & 233,7 & 9,8 & Silva et al. (2011, p. 160) \\
Média & 135,9 & 863,4 & 49,1 & 506,3 & 367,1 & 7,1 & Silva et al. (2013, p. 56) \\
& 150,0 & 811,4 & 74,1 & 421,2 & 281,0 & 16,2 & Goes Neto (2014, p. 32) \\
& 166,0 & 841,8 & 63,8 & 445,5 & 287,9 & 33,4 & \\
Mandacaru & 172,1 & - & 114,1 & 504,9 & - & 22,2 & Cavalcanti e Resende (2006b, p. 405) \\
& 275,1 & 859,3 & 86,2 & 375,6 & 303,7 & 12,0 & Silva et al. (2010b, p. 125) \\
& 269,5 & 866,0 & 77,1 & 430,0 & 336,5 & 12,2 & Silva et al. (2011, p. 160) \\
Média & 164,3 & 894,9 & 81,7 & 530,2 & 416,1 & 16,7 & Silva et al. (2013, p. 56) \\
Facheiro & 208,8 & 851,8 & 82,0 & 443,0 & 324,7 & 16,2 & Goes Neto (2014, p. 32) \\
\hline
\end{tabular}

MS: matéria seca; MO: matéria orgânica; PB: proteína bruta; FB: fibra bruta; FDN: fibra em detergente neutro; FDA: fibra em detergente ácido; EE: extrato etéreo.

MS: dry matter; MO: organic matter; PB: crude protein; FB: crude fiber; FDN: neutral detergent fiber; FDA: acid detergent fiber; EE: ethereal extract.

dos durante um período de 31 dias. Todavia, Silva et al. (2017, p. 764) avaliando a aceitabilidade de novilhas Girolando e valor nutricional da palma Orelha de Elefante Mexicana armazenada por diferentes períodos, não encontraram diferença para matéria orgânica, proteina bruta, fibra em detergente neutro corrigido para cinzas e proteína, carboidratos não fibrosos, carboidratos totais, extrato etéreo e matéria mineral nos diferentes tempos de armazenamento $(0,7,14$ e 21 dias), exceto para matéria seca e fibra em detergente neutro indigistível. O consumo e a digestibilidade também não diferiram em relação ao tratamento testemunha, indicando que qualquer um dos períodos de armazenamento podem ser usados sem interferência no desempenho animal (Silva et al. 2017, p. 765). Carvalho (2017, p. 51) ao estudar a composição química de variedades de palma forrageira também submetidas a diferentes períodos de armazenamento pós-colheita $(0,15,30,45$ e 60 dias), relata que a variedade Miúda e Orelha de Elefante Mexicana podem ser armazenadas até 60 dias, mantendo-se estáveis quanto a composição química, principalmente para as variáveis matéria seca, proteína bruta, extrato etéreo, sódio e potássio.

\section{CONSIDERAÇÕES FINAIS}

A colheita e o fornecimento diário das cactáceas aos animais, aumenta a mão de obra e consequentemente os custos de produção na propriedade. O local de armazenamento das cactáceas pode ser em galpão ventilado ou debaixo de uma árvore com sombra vigorosa. O armazenamento de cactáceas não interfere na qualidade nutricional das cactáceas, podendo ser feito por um período de até 60 dias sem perdas relevantes nos teores nutricionais da planta, não comprometendo o consumo e a produção animal. No entanto, há necessidade de mais estudos sobre o tempo de armazenamento de cactáceas, bem como o efeito desses alimentos após o armazenamento no desempenho animal.

\section{BIBLIOGRAFIA}

Bravo Filho, ES, Santana, MC, Santos, PAA, \& Ribeiro, AS 2018, 'Levantamento etnobotânico da família Cactaceae no estado de Sergipe', Revista Fitos Eletrônica, vol. 12, no. 1, pp. 41-53.

Carvalho, CBM 2017, 'Estratégias de conservação de palma forrageira', Dissertação de Mestrado, Universidade Federal do Piauí.

Cavalcante, LAD, Santos, GRA, Silva, LM, Fagundes, JL \& Silva, MA 2014, 'Respostas de genótipos de palma forrageira a diferentes densidades de cultivo', Pesquisa Agropecuária Tropical, vol. 44, no. 4, pp. 424-433.

Cavalcanti, NB \& Resende, GM 2006a, 'Efeito de diferentes substratos no desenvolvimento do mandacaru sem espinhos (Cereus hildemannianus K. Schum)', Revista Caatinga, vol. 19, no. 3, pp. 255-260.

Cavalcanti, NB \& Resende, GM 2006b, 'Consumo do mandacaru (Cereus Jamacaru P. DC.) por caprinos na época da seca no semiárido de Pernambuco', Revista Caatinga, vol. 9, no. 4, pp. 402-408.

Cavalcanti, NB \& Resende, GM 2007, 'Consumo de xiquexique (Pilocereus gounellei (a. weber ex k. schum.) bly. ex rowl) por caprinos no semiárido da Bahia', Revista Caatinga, vol. 20, no. 1, pp. 22-27.

Ferreira, MA, Silva, FM, Bispo, SV \& Azevedo, M 2009, 'Estratégias na suplementação de vacas leiteiras no semiárido do Brasil', Revista Brasileira de Zootecnia, vol. 38, pp. 322-329.

Góes Neto, PED 2014, 'Desempenho de cabras leiteiras alimentadas com diferentes espécies de cactáceas', Dissertação de Mestrado, Universidade Federal do Rio Grande do Norte.

Lima Júnior, DM, Rangel, AHN, Urbano, SA, Oliveira, JPF \& Araújo, TLA 2013, 'Silagem para vacas leiteiras no semiárido', Agropecuária Científica no Semiárido, vol. 9, no. 2, pp. 33-42.

Lucena, CM, Costa, GM, Sousa, RF, Carvalho, TKN, Marreiros, NA, Alves, CAB., Pereira, DD \& Lucena, RFP 2012, 'Conhecimento local sobre cactáceas em comunidades rurais na mesorregião do sertão da Paraíba (Nordeste, Brasil)', Revista Biotemas, vol. 25, no. 3, pp. 281-291.

Lüttge, U 2011, 'Ability of crassulacean acid metabolism plants to overcome interacting stresses in tropical environments', Aobplants, vol. 2010, pp. 1-15. 
Macedo, AJS, Santos, EM, Oliveira, JS, \& Perazzo, AF 2017, 'Produção de silagem na forma de ração à base de palma: Revisão de Literatura', Revista Electrónica de Veterinaria, vol. 18, no. 9, pp. 1-11.

Magalhães, RMF 2014, 'Manejoe composição químico-bromatológica de Pilosocereus gounellei, em caatinga no sertão cearense', Dissertação de Mestrado, Universidade Federal do Ceará.

Neto, JP, Soares, PC, Batista, AMV, Andrade, SFJ, Andrade, RPX, Lucena, RB, \& Guim, A 2016, 'Balanço hídrico e excreção renal de metabólitos em ovinos alimentados com palma forrageira (Nopalea cochenillifera Salm Dyck)', Revista Pesquisa Veterinária Brasileira, vol. 36, no. 4, pp. 322-328.

Nogueira, MS, Santos, EM, Araújo, GGL, Pinho, RMA, Nunes, CSSM \& Parente, HN 2016, 'Ensilagem de Palma Forrageira', in Santos, EM, Parente, HN, Oliveira, IS \& Parente, MOM (Org.), Ensilagem de Plantas Forrageiras para o Semiárido, EDUFMA, São Luiz, MA.

Nunes, CS 2011, 'Usos e aplicações da palma forrageira como uma grande fonte de economia para o semiárido nordestino', Revista Verde, vol. 6, no. 1, pp. 58-66.

Oliveira, ASC, Cavalcante Filho, FN, Rangel, AHN \& Lopes, KBP 2011 , 'A palma forrageira: alternativa para o semiárido', Revista Verde, vol. 6, no. 3, pp. 49-58.

Peixoto, MJA, Carneiro, MDS, Amorim, DS, Edvan, RL, Pereira, ES, \& Costa, MRGF 2018, 'Características agronômicas e composição química da palma forrageira em função de diferentes sistemas de plantio', Archivos de Zootecnia, vol. 67, no. 257, pp. 35-39.

Rocha, RS, Voltolini, TV, \& Gava, CAT 2017, 'Características produtivas e estruturais de genótipos de palma forrageira irrigada em diferentes intervalos de corte', Archivos de Zootecnia, vol. 66, no. 255, pp. 363-371.

Rodrigues, AM, Pitacas, FI, Reis, CMG, \& Blasco, M 2016, 'Nutritional value of Opuntia ficus-indica cladodes from Portuguese ecotypes', Bulgarian Journal of Agricultural Sciences, vol. 22, no. 1, pp. 40-45.

Santana Neto, JA, Castro Filho, ES \& Araújo, HR 2015, 'Potencial das cactáceas como alternativa alimentar para ruminantes no semiárido', Nutritime Revista Eletrônica, vol. 12, no. 6, pp. 4426-4434.

Silva, CCF \& Santos, LC 2006, 'Palma forrageira (Opuntia fícus-indica Mill) como alternativa na alimentação de ruminantes', Revista Eletrônica de Veterinária, vol. 7, no. 10, pp. 1-13.

Silva, JGM, Lima, GFC, Paz, LG, Matos, MMS \& Barreto, MFP 2010a, 'Utilização de cactáceas nativas associadas à silagem de sorgo na alimentação de bovinos'. Revista Centauro, vol. 1, no. 1, p. 1-9.

Silva, JGM, Lima, GFC, Aguiar, EM, Melo, AAS \& Rêgo, MMT 2010b, 'Cactáceas nativas associadas a fenos de flor de seda e sabiá na alimentação de borregos', Revista Caatinga, vol. 23, no. 3, pp. 123-129.

Silva, JGM, Melo, AAS, Rêgo, MMT, Lima, GFC \& Aguiar, EM 2011, 'Cactáceas nativas associadas a fenos de flor de seda e sabiá na alimentação de cabras leiteiras', Revista Caatinga, vol. 24, no. 2, pp. 158-164.

Silva, JGM, Melo, SSNS, Diniz, MCNM, Medeiros, MR, Silva, SYAM \& Araújo, MS 2012, 'Características morfofisiológicas e produção do mandacaru cultivado em diferentes densidades', Revista Centauro, vol. 3, no. 1, p. 33-43.

Silva, JGM, Lima, GFC \& Rêgo, MMT 2013, 'Cactáceas Nativas na Alimentação de Ruminantes', Revista Científica de Produção Animal, vol. 15, no. 1, pp. 53-62.

Silva, TGF, Primo, JTA, Morais, JEF, Diniz, WJS, Souza, CAA \& Silva, MC 2015, 'Crescimento e produtividade de clones de palma forrageira no semiárido e relações com variáveis meteorológicas', Revista Caatinga, vol. 28, no. 2, pp. 10-18.

Silva, ETDS, Melo, AASD, Ferreira, MDA, Oliveira, JCVD, Santos, DCD, Silva, RC \& Inácio, JG 2017, 'Acceptability by Girolando heifers and nutritional value of erect prickly pear stored for different periods', Pesquisa Agropecuária Brasileira, vol. 52, no. 9, pp.761-767.

Soares II, JC \& Silva Júnior, SS 2012, 'Palma forrageira: uma alternativa para sobrevivência no Semiárido', Revista Cabra \& Ovelha, vol. 34, no. 72 , pp. 4-5.

Taiz, L \& Zeiger, E 2013, Fisiologia Vegetal. $5^{a}$ ed., Artmed, Porto Alegre, RS.

Valadares Filho, SC, Pina, DS, Chizzotti, ML \& Valadares, RFD 2006, 'Degradação ruminal da proteína dos alimentos e síntese de proteína microbiana', in Valadares Filho, SC, Paulino, PVR \& Magalhães, KA (ed.), Exigências nutricionais de zebuínos e tabelas de composição de alimentos BR-Corte, Suprema Gráfica, Viçosa, MG.

Wanderley, WL, Ferreira, MA, Andrade, DKB, Véras, ASC, Farias, I, Lima, LE \& Dias, AMA 2002, 'Palma forrageira (Opuntia ficus indica, Mill) em substituição à silagem de sorgo (Sorghum bicolor (L.)) na alimentação de vacas leiteiras', Revista Brasileira de Zootecnia, vol. 31, no. 1, pp. 273-281.

West-Eberhard, M, Smith, JA \& Winter, K 2011, 'Photosynthesis, reorganized', Science, vol. 332, pp. 311-312.

Zappi, D, Taylor, N, Santos, MR \& Larocca, J 2015, 'Cactaceae in Lista de Espécies da Flora do Brasil'. Jardim Botânico do Rio de Janeiro. Disponível em: <http://floradobrasil.jbri.gov.br/jabot/floradobrasil/ $\underline{F B 70}>$. Acesso em: 15 Maio 2018. 